\title{
Self-inflicted bites by two venomous snake species: Medo's pit viper Trimeresurus medoensis and lesser black krait Bungarus lividus
}

\author{
JAYADITYA PURKAYASTHA ${ }^{1 *}$, SOMLEE GUPTA ${ }^{1,2}$, RUPANKAR BHATTACHARJEE ${ }^{1}$ \& SANATH BOHRA ${ }^{1}$ \\ ${ }^{1}$ Help Earth, Guwahati 781007, Assam, India \\ ${ }^{2}$ Department of Biotechnology, Pondicherry University, Puducherry 605014, India \\ *Corresponding author e-mail: jayaditya@gmail.com
}

C ases of self-envenomation in snakes are not uncommon. However, deaths in most cases were associated with stress or internal disease, as evident from necropsies, rather than envenomation alone (Peterson, 1990). Of the cases considered by Peterson (1990) the deaths of Crotalus atrox and Ophiophagus hannah following their own bites were not solely due to venom, while Coniophanes fissidens, Micrurus fulvius tenere, and Bungarus flavicep all survived their bite despite some ill effects. In a case of self-envenomation by Boiga irregularis death appeared to be due to envenomation alone (Hill \& McKillop, 2017). In this report we describe two cases of self-inflicted bites by two venomous snakes both of which subsequently died.

Medo's pit viper Trimeresurus medoensis Zhao, 1977 On 21st August 2011, an adult Trimeresurus medoensis was rescued from a kitchen garden in the Malki area $\left(25^{\circ}\right.$ $\left.33^{\prime} 37.09^{\prime \prime} \mathrm{N}, 91^{\circ} 53^{\prime} 24.01^{\prime \prime} \mathrm{E}\right)$ of Shillong, Meghalaya, India at around 08:00 h. The snake was bagged and was to be released into the nearby forested area the next day. The following morning when the bag was opened to examine the snake, it was found dead, biting its midbody (Fig. 1). The dead specimen was then preserved in $4 \%$ formalin but after 3 days it was noticed that the body posterior to the bite was significantly decomposed while the area anterior to the bite was relatively well preserved. This suggests that death occurred soon after the bite since the venom appears not to have spread throughout the body but was confined. This provides some evidence that the envenomation was the cause of death and that this species is not immune to the effects of its own venom.

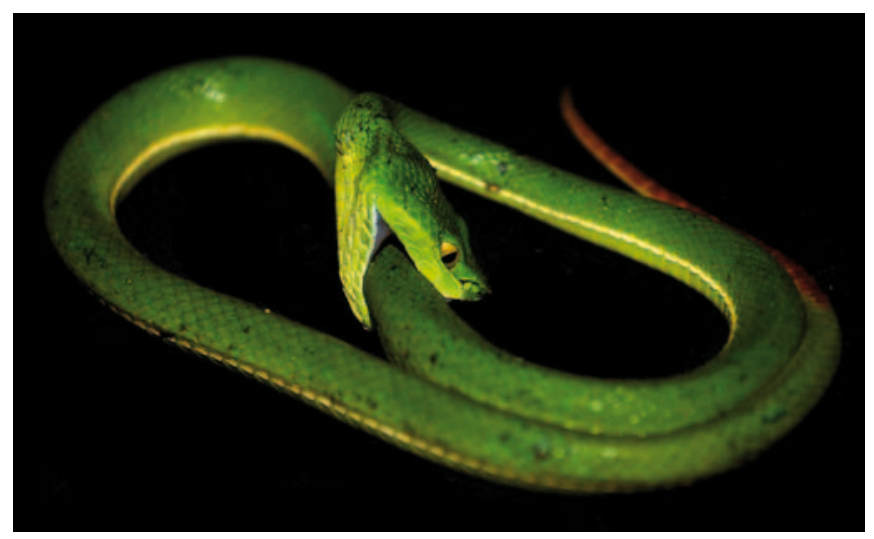

Figure 1. A dead Trimeresurus medoensis following a self-inflicted bite

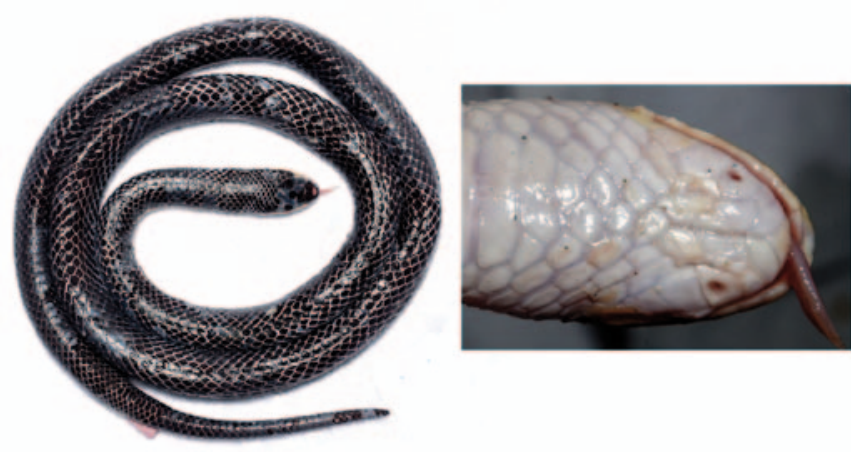

Figure 2. A dead Bungarus lividus following a self-inflicted bite (left); 3 rd infralabials punctured by the fangs (right)

Lesser black krait Bungarus lividus Cantor, 1839

On 4 March 2020, a sub-adult Bungarus lividus was rescued from the Geetanagar area $\left(26^{\circ} 10^{\prime} 15.15^{\prime \prime} \mathrm{N}, 91^{\circ} 47^{\prime} 19.65^{\prime \prime} \mathrm{E}\right)$ of Guwahati, Assam, India. On the way back from the rescue site, the snake was found dead within the bag. Initially we believed that the snake died due to stress or because of coming in contact with carbolic acid sprayed at the rescue location. On closer examination we spotted two puncture marks on the lower lip of the snake just below the fangs (Fig. 2). Apart from the puncture marks, no other visible damage was seen on the snake. It is unclear whether the envenomation was the actual cause of death.

\section{REFERENCES}

Hill, A.G. \& McKillop, L. (2017). Fatal self-envenomation in a brown tree snake, Boiga irregularis, from south-east Queensland. Toxicon 126: 1-3.

Nichol, A.A., Douglas, V. \& Peck, L. (1933). On the immunity of rattlesnakes to their venoms. Copeia 4: 211-213.

Peterson, K.H. (1990). Conspecific and self-envenomation in snakes. Bulletin of Chicago Herpetological Society 25: 2628. 